Lekashvili, E., \& Mamaladze, L. (2018). Crypto currency - a new challenge for the economy of Georgia. Copernican Journal of Finance \& Accounting, 7(4), 87-97. http://dx.doi.org/10.12775/ CJFA.2018.022

\author{
Eka LeKashVILI* \\ Ivane Javakhishvili Tbilisi State University
}

\author{
Lela Mamaladze ${ }^{* *}$ \\ Ivane Javakhishvili Tbilisi State University
}

\title{
CRYPTO CURRENCY - \\ A NEW CHALLENGE FOR THE ECONOMY OF GEORGIA
}

Keywords: cryptographic currency, electronic money, legal regulation, blocks chain, bitcoin.

J E L Classification: E00, E42, E52, E58, F10, G00.

\begin{abstract}
The popularity of electronic currencies on the world innovative technology market increases daily. The history of currency development and the need for additional monetary means has led to the creation of a crypto currency that has had a substantial impact on the financial world. The world's largest companies have received crypto currency in the form of payment. At the same time, in a number of states the creation of regulatory legislative acts on virtual currency is underway. The paper aims to study a cryptographic currency and its positive and negative consequences, main trends of development in the world and particularly, in Georgia. The paper is based on the quali-
\end{abstract}

Date of submission: February 13, 2019; date of acceptance: March 19, 2019.

* Contact information: eka.lekashvili@tsu.ge, Ivane Javakhishvili Tbilisi State University, Tbilisi, Georgia, phone: +995599899809; ORCID ID: https://orcid.org/00000001-9781-7620.

${ }^{* *}$ Contact information: lela.mamaladze@gmail.com, Ivane Javakhishvili Tbilisi State University, Tbilisi, Georgia, phone: +995595142001; ORCID ID: https://orcid.org/00000002-8037-3856. 
tative and quantitative methods of research. Also, we have analyzed the content of the legal documents. We used the method of statistical analysis and the reviewed practical examples of other countries. In addition, we used questionnaires and interviews of civil society members in Georgia for gathering information and to assess the tendency of public attitudes toward crypto currencies. Georgia can be said to be an emerging space for the development of cryptographic currency market because there is no adequately developed regulatory framework, there is a huge risk for a sustainable and inclusive development of the economy, as well as the public and its welfare. The question of regulation of cryptographic currency is problematic for all countries, including Georgia, because it is the case when the theoretical issue is not properly studied and consequently it is difficult to develop adequate policies. Based on the research we can conclude that the establishment of crypto currency is a serious threat to the central banks to produce official macro-economic statistics, which creates problems for the correct implementation of monetary policy. At the present stage there is no joint approach to regulating virtual currencies. However, the central banks of the world continue to cooperate in formulating a common approach.

\section{IIINTRODUCTION}

The popularity of electronic currencies on the world innovative technology market increases daily. The traditional structure of public administration in the era of digital and technological development is not effective (Lekashvili, 2018). The history of currency development and the need for additional monetary means has led to the creation of a crypto currency that has had a substantial impact on the financial world. Through the cryptographic currency, products and services are more available. The world's largest companies have received crypto currency in the form of payment. The number of block chain users is increasing (figure 1). At the same time, in a number of states the creation of regulatory legislative acts on virtual currency is underway.

Georgia is gradually involved in these processes. According to E-money ${ }^{1}$, the number of Bitcoin consumers increased from 2016 to 2017 by $400 \%$ and from 2016 to 2017 by $130 \%$. Rapid growth rates of crypto currency consumers and the imperfection of studying the phenomenon makes the issue of research important.

${ }^{1}$ Georgian multicultural electronic wallet, which first introduced Georgia in 2015 to buy, sell, send and sell virtual currencies of virtual currency. 
Figure 1. Number of Block chain wallet users worldwide from 1st quarter 2015 to 4 th quarter 2018

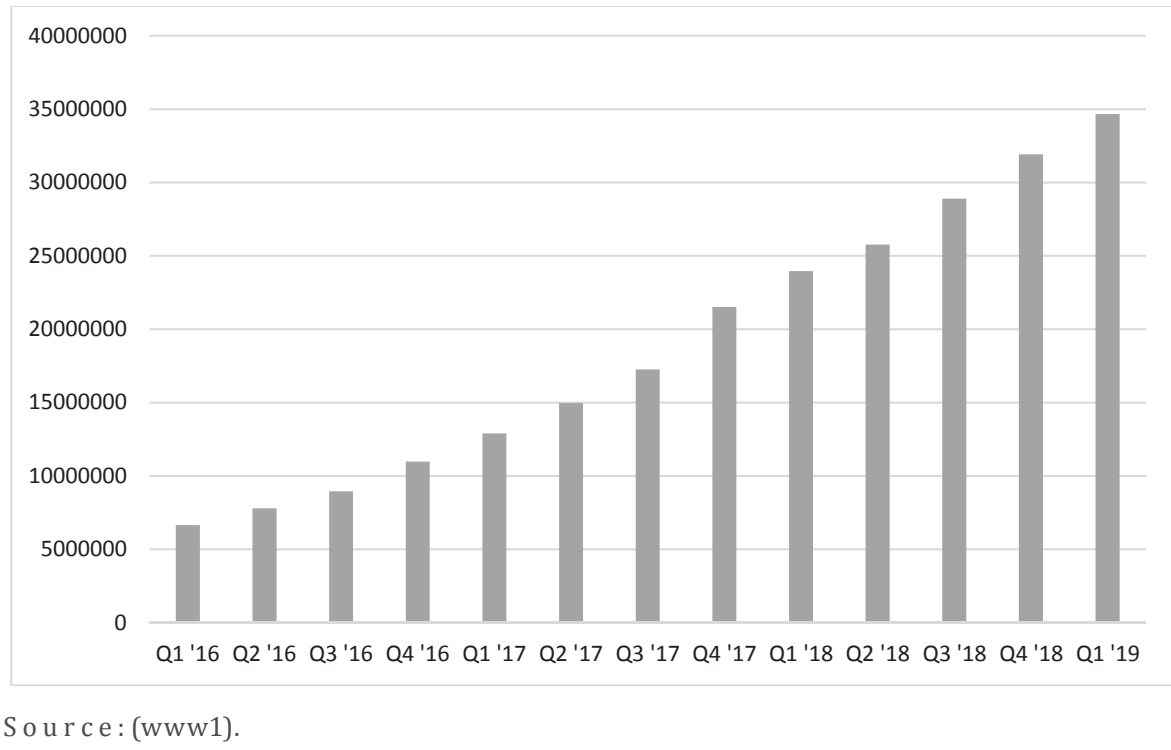

\section{THE RESEARCH METHODOLOGY AND THE COURSE OF THE RESEARCH PROCESS}

The research aim is to study a cryptographic currency's positive and negative consequences, main trends of its development on example of Georgia. Georgia, as a developing country with a Soviet experience, faces great difficulties in solving financial problems. Smaller countries, that have open and less diversified economies, tend to have a serious impact on interdependent and integrative processes (Lekashvili \& Gaprindashvili, 2014).

To achieve the above goals we have identified the following tasks:

- To study the evolution, essence and regulation of cryptographic currency;

- To analyze legislative bases of foreign experience;

- To identify risks associated with cryptographic currencies for elaboration of effective regulatory methods;

- To study the public attitude towards crypto currency in Georgia and identification of currency policies challenges.

In the research process we used interdisciplinary methods of research. The research is based on studying, research and analysis of scientific literature on 
the topic of study. The paper includes the works of Georgian and foreign scientists related to this topic and reports of international organizations. In the process of questioning, we had consultations with field experts in the questionnaire.

Also, in order to conduct research, we use the quantitative research method, determined method with combination of Judgmental Sampling and Snowball Sampling. During the interviews had been used electronic form with questionable survey tool. The survey was carried out in October 2018.

First of all, we have selected interviewers, who own a crypto currency and then they connected in research other respondents. The questionnaire was sent to the targeted individuals who have crypto currency or possess certain knowledge about it.

The questionnaire was consisted of 10 questions; each has an approximate answer and open responses, which gives the respondent an opportunity to express his opinion. The survey involved 90 respondents. Their attitudes should be taken into consideration for the creation of effective mechanisms for regulating the cryptographic market for the government, as well as for people interested in the topic.

It could be mentioned, that the scientific study complicates the lack of statistical data. Besides, there are no clearly defined statistical indicators that would allow us to use the concrete method in the research. Because a popularity of virtual currency is increasing, there are a lot of literature, research and special statements created on the issue in which the contradictory positions are presented.

\section{THE EVOLUTION, CLASSIFICATION}

\section{AND FUNCTIONALITY OF CRYPTOGRAPHIC CURRENCY}

Some researchers think that we can review the existing literature on the virtual currency from the 19th century, giving the basis its anarchic structure, decentralized character and the lack of regulatory mechanism from the government (Proudhon, 1890).

According to Friedrich von Hayek (1976), the production of money, as a normal commercial product, should have been market-based and not by a state monopoly. Later, the idea started in the 1990s when Cryptography was used by David Chaum in the system created by DigiCash for pay-settlement. After that, programmer Wei Dai wrote a cryptosocial program (www2). 
In the early stages of Bitcoin's creation in 2008, economist Paul Krugman and some researchers estimated the phenomenon of the virtual currency as an instrument of financial pyramid and speculation, and assessing it as a risky venture (www3). In 2009, Satoshi Nakamoto ${ }^{2}$ created the most common virtual currency - Bitcoin. Well-known American financier Larry Fink called Bitcoin "money laundering index". In his opinion, the increase in bitcoin price shows how big is the world's demand for money laundering (www4).

In 2013, Chairman of the Board of Directors of Google, Eric Emerson Schmidt and Jared Cohen published the book "New Digital Era", where the risks are discussed that may be accompanied by the general availability of Cyberworld (Schmidt \& Cohen, 2013).

With the spread of cryptocurrency, the contradiction of opinions around the issue increases. Some scientists think that in case of virtual money we deal with financial pyramid. Others - that the future of cryptocurrency depends on the regulators (Kenneth Rogoff, Robert Merton), because unreliable and of lack of security (www5).

According to the classification of the European Central Bank, "Virtual currency is the type of unregulated digital money, whose output and regular control is carried out by their creators and used by specific virtual community members" (European Central Bank, 2012). Also, in case of decentralized system digital currency is created with a predefined algorithm, and there is no central institution that can influence money emissions (Greenberg, 2011).

The approaches are different from the states and what among the EU countries too. Member states and legislators agree to take strict measures regarding bitcoin in order to eliminate money laundering and terrorism financing by the EU. The EU lawmakers supported the prohibition of anonymous transfers to be paid by advance payment cards. This decision of the European Union is due to the rapid growth of the Bitcoin course (www6).

The ECB document examines the possibilities of virtual currency schemes to perform the following functions of the central bank: a) price stability; B) financial stability; c) the stability of the payment system (European Central Bank, 2012). The report says that the user must be fully informed about the risks associated with the virtual currency and the expected financial loss, as there is no specific legal protection that reimburses the loss of the consumer.

2 Satoshi Nakamoto is the name used by the unknown person or people who developed Bitcoin. 
The focus is on hacker threats and insurmountable transactions, which can not be canceled in case of error. The document refers to the rapid change in the value of the virtual currency and the risk of incorporation into illegal activities due to users' anonymity (European Banking Authority, 2014).

The United States is considered to be one of the major markets for the distribution of cryptographic currency. In 2014, New York State Financial Services Department has developed consumer protection, money laundering and safety rules for virtual currency businesses. New types of licenses (called "BitLicenses") will require individuals who perform such activities as virtual currency exchange and send / transfer to clients (Ellis, 2013).

Based on the study of many cases (China, Thailand, Russia, Bolivia and est.) and systematization of the research problem, we can assume that the issue of cryptocurrency is not theoretically considered and it is very difficult to create some regulations. So crypto currency is a high-risk investment, with high profits. cryptocurrency market is controlled by no one, and it is only a mechanism to regulate the market, respectively, characterized by strong price volatility and create favorable conditions for unsecure transactions. The legal status of bitcoin is substantially different in countries. Some of them have allowed it to be used for trade and other purposes, while others have been banned. Regulations and prohibitions that apply to bitcoin may be extended to other crypto currencies.

\section{Cryptocurrency in Georgia - New Challenge for Currency Policy}

The development of the cryptocurrency market in Georgia confirms the growth of the number of customers. In particular, the number of bitcoin consumers increased by $400 \%$ from 2015 to 2016, from 2016 to 2017 by 130\% (www7). In June 2017, the first Georgian cryptocurrency was created (Golden Fleece), which aims to build a cryptocurrency output database on the Black Sea coast of Georgia.

Bitfury is one of the largest block chain companies offering a variety of services and also produces bitcoin. Bitfury Holding owns free economic zone in Georgia. The company owns two blocks in Gori and Tbilisi.

Considering that Georgia was one of the first states, the implementation of blockchain technology can be assessed as a challenge, since any innovative technology is required to assess the accompanying risk factors as well as the definition and establishment of relevant concepts at the legislative level. It should be note that the number of legal institutions around the world is limited to the definition of blockchain technology. 
The virtual currency in Georgia is growing in popularity. However, like many other states, it is not a legal means of payment in Georgia. Despite the position of the National Bank, in October 2018, the Cryptomotive ATM operator Krimmottom appeared on public places.

Georgia is one of the leading countries in the mining industry, including electricity consumption. In September 2018, a large scale digital summit was held in Georgia, which was attended by Block chain industry specialists and founders of the mining centers. The aim of the meeting was to share practical and theoretical experiences and ideas. The event was considered eco-mining the most important challenge for the mainstreaming sector (www8).

According to the latest (2018) research conducted by the Georgian Foundation for Strategy and International Studies, electricity consumption in Georgia in 2017 is $7.7 \%$ compared to the previous year and $14.4 \%$ by 2015 , which is related to the production of Bitcoins. There are 1800 Bitcoins available every day in the world, with a bigger share of one company registered in Georgia - BitFury. In total, Georgia comes to about $15 \%$ of world production of bitcoin, or about 270 daily, and up to 100,000 Bitcoins a year. It should be taken into account that apart from BitFury, other companies are also able to find Bitcoin in Georgia, which is not accounted for. Besides, there are no annual reports of Georgian producers of bitcoin available in public space.

The public opinion survey on Cryptocurrencyis argued by the hypothesis that the action of the state should be acceptable to the public, including the regulation of the cryptographic market. The research aims to study the attitude of citizens towards the issue. The study covered almost every age category or social status (90 respondents), allowing the results to be made public on the whole community.

The age groups of respondents were as follows: $18-35-43 \%, 35-45-33 \%$, 45-65 - 18\%, 65 above 6\% (figure 2). As for social status, we received similar data: student $-26 \%$, employed $-65 \%$, unemployed $-4 \%$, pensioner $-5 \%$ (figure 3$)$. With the next question we tried to find out how many respondents were educated in the direction of economics or information technology, or whether their activities were related to any of the above-mentioned fields: Economic education $-31 \%$, Information Technology specialist - 19\%, both $-12 \%$, none - $28 \%$ (figure 4 ). $50 \%$ of respondents have full information about crypo currency, $36 \%$ have incomplete information and $14 \%$ do not have any information

As regards the investor's attitude towards virtual currency, 22\% think that it is risky and does not support 18\% does not have a specific answer, 25\% 
thinks that in case of finding financial resources, he would try to gain profit via virtual currency, while the remaining $35 \%$ are members of society that own a currency or mainers (figure 5).

\section{Figure 2. Age}

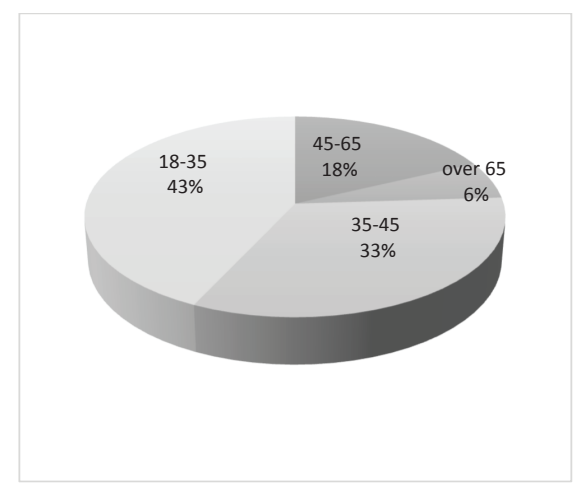

Figure 3. Employment status

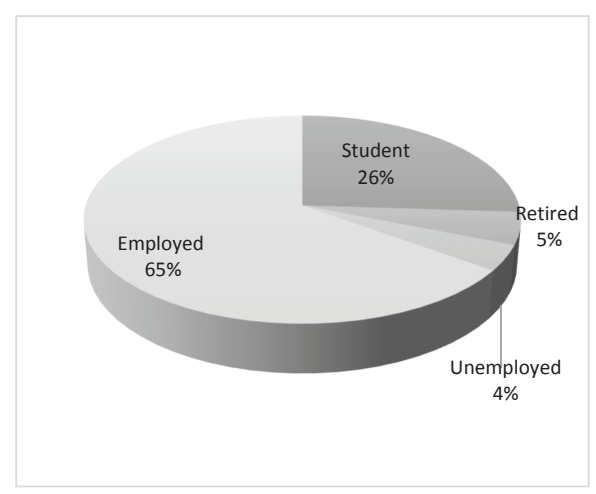

S o u r c e : worked out by authors based on own research.

Figure 4. Education

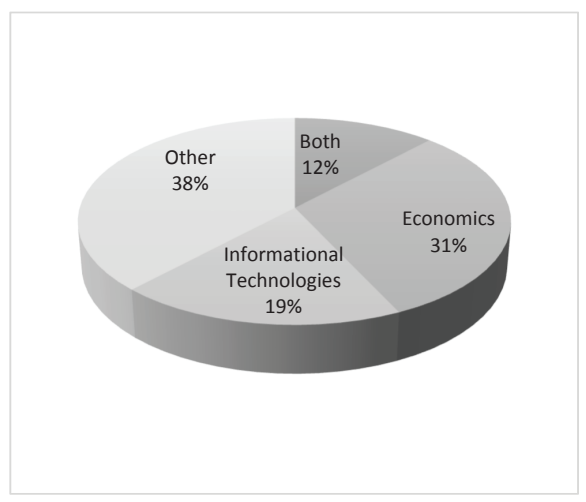

Figure 5. Invest in crypto currencies

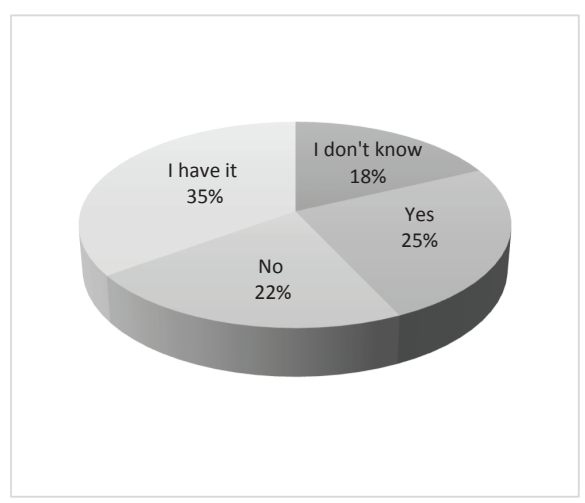

S o u r c e : worked out by authors based on own research.

The part of the interviewees, who are themselves virtual currency holders, have asked us to name what they have chosen to do. The data was distributed as follows: $65 \%$ - Bitcoin, $13 \%$ - Ripple, $12 \%$ - Etherium, $10 \%$ - other. We 
asked the same segment of the respondents to identify the disadvantages that we have received as a result of the cryptocurrency: frequent variability of the crypto currency course (30\%), dangerous cyber attacks (45\%), the risk of unprotected transactions (25\%) (figure 6).

In response to the same respondents we have determined the frequency of transactions: at least once a month $-28 \%$, once in a few months $-44 \%$, no transaction $-28 \%$ (figure 7 ). $60 \%$ of respondents think that it is profitable, $22 \%$ is lucrative, $18 \%$ find it hard to answer.

Finally, we asked respondents whether the government should consult with the public before forming the norms for virtual currency regulation. The majority of respondents (42\%) agree that any public issue is necessary for legislators to communicate with citizens and to take into consideration their opinions, 38\% thinks it is much more important to consult with people who are deeply aware of the issue, and 16\% believe that crypto currency don't need any regulation and control mechanisms.

Figure 6. Risks

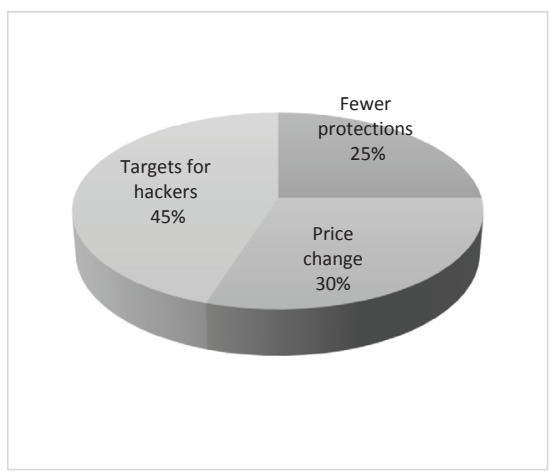

Figure 7. Transaction per month

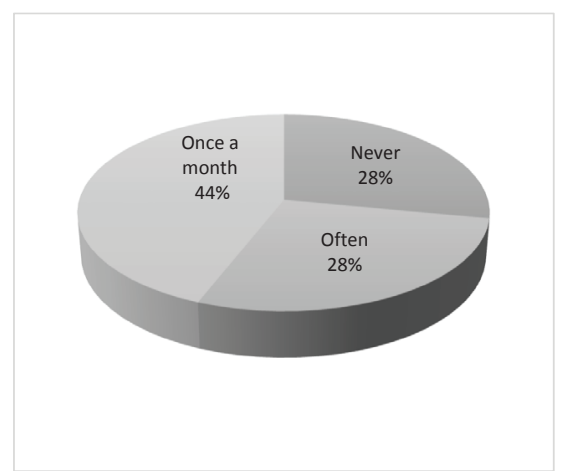

S o u r c e : worked out by authors based on own research.

Based on the results of the research, it can be said that the public has a great interest in cryptocurrency. Taking into consideration that the virtual currency in the Georgian reality has been established in recent years, their awareness level is quite high in the above mentioned issue. However, the generalization of the results of the research will not be valid and can not give us a complete picture of the following reasons: on the one hand the small number of respondents were interviewed and on the other hand, the survey will be conducted in one 
of the social networks, where the owners of the crypto currency and the interested persons are joined.

\section{CONCLUSIONS}

In conclusion, Georgia is an emerging space for the development of cryptographic currency market because there is no adequately developed regulatory framework, there is a huge risk for a sustainable and inclusive development of the economy, as well as the public and its welfare. Based on the research we can conclude that the establishment of crypto currency is a serious threat to the central banks to produce official macro-economic statistics, which creates problems for the correct implementation of monetary policy. At the present stage there is no joint approach to regulating virtual currencies. However, the central banks of the world continue to cooperate in formulating a common approach.

Based on the summarization of the issue, we can outline the following challenges with the cryptography industry in Georgia:

- State approach and legal regulation issues;

- There are a number of uncertainties about terminological definitions and that is why it is necessary to share foreign experience and to improve the issue;

- Maintain stability of the financial system. The growing tendency of the development of the cryptocurrency system, which creates an alternative to the traditional financial and banking spheres, may be a causative factor for the chaos of the financial market;

- High power consumption, in case of a similar pace, will have a serious impact on climate change;

- Difficulties in predicting the nominal value of crypto currency.

\section{REFERENCES}

Ellis, S. (2013). A Cryptography Primer. Chicago: Cura Corporation.

European Banking Authority (2014). EBA Opinion on 'virtual currencies'. http://eba. europa.eu/documents/10180/657547/EBA-Op-2014-08+Opinion+on+Virtual+Cur rencies.pdf (accessed: 10.12.2018).

European Central Bank (2012). Virtual Currency Schemes. Frankfurt am Main: Eurosystem, http://www.ecb.europa.eu/pub/pdf/other/virtualcurrencyschemes201210en. pdf (accessed: 10.12.2018). 
Greenberg, A. (2011). Crypto Currency, http://www.forbes.com/forbes/2011/0509/ technology-psilocybin-bitcoins-gavin-andresen-crypto-currency.html (accessed: 10.12.2018).

Hayek, F. (1976). Denationalization of Money: An Analysis of the Theory and Practice of Concurrent Currencies. Institute of Economic Affairs.

Lekashvili, E., \& Gaprindashvili, G. (2014). Social Integration in the Context of Regional Economic Integration (On the Example of the South Caucasian States). In A. Biagini, G. Motta (Eds.). Empires and Nations from the $18^{\text {th }}$ to the $20^{\text {th }}$ century. Volume 2. Cambridge: Cambridge Scholars Publishing.

Lekashvili, E. (2018). E-Governance and Economics Curricula Modernization Needs at Tbilisi State University. IV International Scientific and Practical Conference „Strategic Imperatives of Modern Managements (SIMM - 2018), 19-20 April 2018 and Round Table „Digital Economy: Threats, Opportunities and Education's Calls”, Kiev National Economic University named after Vadym Hetman, Singulatoryu Kiev Chapter, Kiev.

Proudhon, P.-J. (1890). What is property? An Inquiry into the Principle of Right and of Government. Humboldt Publishing Company.

Schmidt, E., \& Cohen, J. (2013). The new digital age: reshaping the future of people, nations and business.

(www1) Statista, http://www.statista.com/statistics/647374/worldwide-blockchainwallet-users (accessed: 10.12.2018).

(www2) The Guardian, http://www.theguardian.com/technology/2003/feb/25/comment.comment (accessed: 20.02.2018).

(www3) Business Insider, http://www.businessinsider.com/paul-krugman-says-bitcoin-is-a-bubble-2017-12 (accessed: 20.02.2018).

(www4) CNBC, http://www.cnbc.com/2017/10/13/blackrock-ceo-larry-fink-calls-bitcoin-an-index-of-money-laundering.html (accessed: 20.02.2018).

(www5) PBS, http://www.pbs.org/newshour/economy/making-sense/why-a-nobellaureate-in-economics-thinks-bitcoin-is-toast (accessed: 10.12.2018).

(www6) Reuters, http//www.reuters.com/article/uk-eu-moneylaundering/eu-agreesclampdown-on-bitcoin-platforms-to-tackle-money-laundering-idUSKBN1E928M (Accessed: 10.12.2018).

(www7) Sazogadoeba, http://www.sazogadoeba.ge/index.php?post_id=2684 (accessed: 10.12.2018).

(www8) Cryptoworld, http://cryptoworld.ge/\%E1\%83\%A1\%E1\%83\%90\%E1\%83\%9 B\%E1\%83\%98\%E1\%83\%A2\%E1\%83\%98-bitmain (accessed: 10.12.2018). 